\title{
LA EMISIÓN NÚMIDA DE SigA (SS. II-I A.C.) CON JINETE LANCEANDO
}

DAVID MARTÍNEZ CHICO ${ }^{1}$, LAURENT CALLEGARIN $^{2}$

(1) Universitat de València.david_ele@live.com

(2) Université de Pau et des pays de l'Adour - Casa de Velázquez. laurent.callegarin@ casadevelazquez.org

A finales de 2014 pudimos acceder a una colección jienense, en la que documentamos esta pieza singular, que probablemente procede de Andalucía. La moneda (fig. 1) pesa 3,02 g, mide unos $16 \mathrm{~mm}$ y tiene un eje de 10 horas. Pertenece a una emisión no estudiada, sin que esté descrita en ninguna obra de referencia sobre el mundo númida (Müller 1860; Mazard 1955; Jenkins 1969; Alexandropoulos 2007).
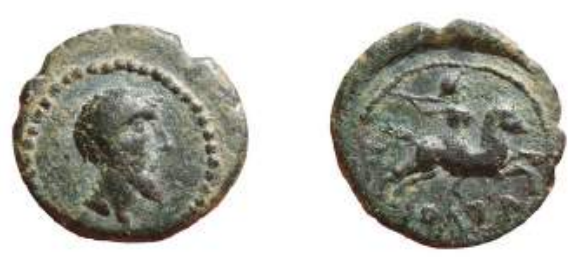

Fig. 1: Colección privada (ex Lucernae, venta en eBay \#291320924221, visitada 09/12/2014).

En el anverso muestra un busto masculino y barbado a derecha (al parecer con repinte, dando la sensación de tener dos barbas) y en el reverso un jinete con casco a caballo, sosteniendo una jabalina en actitud de lanzarla, también hacia la derecha; y la leyenda curvada $S Y^{\prime} G^{\prime} \mathrm{N}^{1}$ bajo el caballo, en el exergo, pero en mal estado de conservación. Ambas caras poseen gráfilas punteadas, siendo la del anverso más gruesa.

El análisis iconográfico se hace vital, en tanto en cuanto nos determina su emisor. El busto del anverso tiene precedentes en otras acuñaciones númidas, más concretamente en monedas de algunos de sus primeros reyes, conocidos por la fuentes literarias, como los masilios Masinisa o Micipsa (203-148 / 148-118 a.C.) (Alexandropoulos 2007: $396, n^{\circ} 11$ y lám. 5) y sobre todo el masesilo Sifax (¿?-202 a.C.) (fig. 2). Concretamente las amonedaciones que más paralelos iconográficos guardan fueron emitidas de acuerdo a una metrología de cuartos (Alexandropoulos 2007: 393, nº 3 y lám. 5; Id.: 398, no 19 y lám. 6).
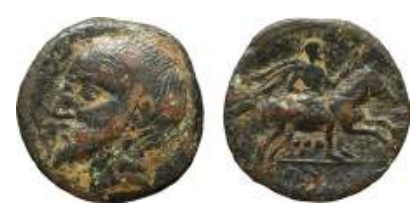

Fig. 2: Bronce de Sifax (tipo Mazard 1955: $\mathrm{n}^{\circ}$ 6). British Museum. 1867.1109.130 (Foto: L. Callegarin). Medidas: 3,31 g / 19 mm / 12h. 
Sin embargo, el busto barbado del anverso de nuestra moneda, y a diferencia de las emisiones númidas masesilas, no presenta una cinta o láurea, motivo de la realeza. A pesar de ello, el anverso de esta emisión adopta una influencia de indudable sabor masesilo, amén del rostro norteafricano y la barba espesa y puntiaguda. El reverso es asimismo, muy significativo, incluso como fuente primaria histórica, al materializar las palabras de Tito Livio $(35,11,7)$, quien describió a los jinetes númidas como medio desnudos, sin llevar más armas que sus jabalinas ${ }^{2}$. A pesar de esto, la imagen de nuestro jinete presenta muchos más detalles, pues monta a pelo, lleva casco, pantalones sueltos y quizás también un pectoral.

Tal y como está dispuesto el jinete, su semejanza numismática más directa ${ }^{3}$ se encuentra en el reverso de unos bronces emitidos teóricamente en Siga por Sifax (213-202 a.C.) (Alexandropoulos 2007: 393, no 2 y 3 y lám. 5; Alexandropoulos 2013: 21). Hablamos, en efecto, de las piezas reseñadas por Mazard (1955: $n^{\circ}$ 4, 5, 6, 8 y 9), con la leyenda SPQ HMMLKT en cartela rectangular y la presencia de cinco, cuatro, tres, dos y un glóbulos respectivamente como marcas de valor o emisión (Alexandropoulos 2007: 393); de este modo y según Alexandropoulos (2007: 393), sólo las que poseen un glóbulo pueden considerarse como cuartos de unidad (de $3,0 \mathrm{~g}$ ) y unidades (de 10-12 g), mientras que las otras restantes mitades de unidad (de 6,0 g).

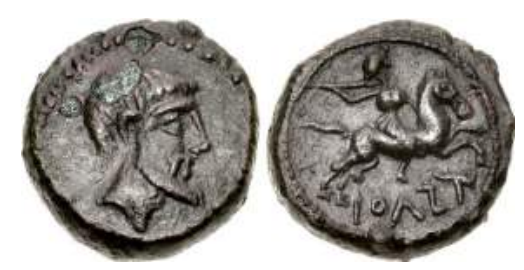

Fig. 3: Segundo ejemplar conocido (CNG 7/10/2015, lote 1615).

La leyenda curvada bajo el caballo se encuentra bastante deteriorada. Afortunadamente, la confirmación de la leyenda ha venido de la mano de una segunda pieza, subastada en Classical Numismatic Group (7/10/2015, lote 1615) (fig. 3), con 4,03 g, 14 mm y 10 h también. Este segundo ejemplar permite leer la leyenda neopúnica como ȘY'N, es decir, alusiva a la ciudad de Siga ${ }^{4}$. La mencionada casa de subastas ya sugirió que era inédita.

Profundizando en la historiografía de las piezas númidas, más concretamente las referentes a Boco I (110-80 a.C.) y sus sucesores ( $c a$. 80-33 a.C.), comprobamos que esta pieza guarda alguna semejanza con la número 578 de Mazard (1955: ${ }^{\circ} 578=$ Alexandropoulos 2007: 406, n 44 y lám. 7). Esta pieza, sin embargo, fue descrita por los citados autores en interrogación con cabeza real y caballo parado a derecha. Hemos de suponer que Alexandropoulos sólo recoge el dibujo presente en la obra de Mazard (fig. 4, A) y puede deducirse que el dibujo de Mazard (1955: 175 y $257, n^{\circ} 578$ ), idealiza el tipo monetario, pues no se trata de un caballo, sino de un toro o carnero (fig. 4 , B). Tanto la destacada gráfila punteada y gruesa del anverso, como la caracterización del busto barbado y el "caballo" con orejas terminadas en antenas, además de sus comunes medidas (3,06 g, $17 \mathrm{~mm}$ y 12h), posiblemente sugieran estar ante una metrología similar a nuestra serie.

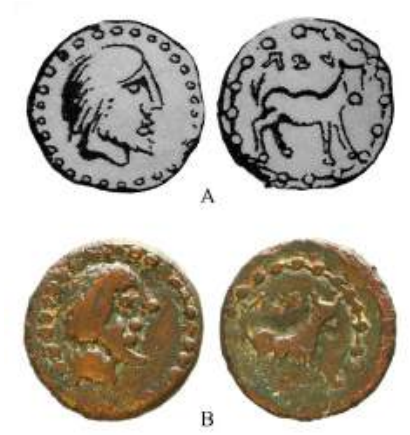

Fig. 4: Moneda de Siga con leyenda neopúnica SYG: A. Dibujo según Mazard (1955: $n^{\circ}$ 578); B. Ejemplar inv. R188 de la Bibliothèque Nationale de France (Foto: L. Callegarin).

Sin embargo, determinar las cronologías de las emisiones númidas entraña serias dificultades. Simplemente la asociación de un reinado con ciertas monedas es una labor, en la mayoría de los casos, imposible, al no existir la titulatura del rey en la mayoría de las piezas. Esto provoca que las dataciones sean más bien laxas y a veces jalonadas entre distintos reinados. Este es el caso de las emisiones de Masinisa y Micipsa, y Boco I y Boco II (cuya titulatura, existente para este último caso, es la misma). Idéntica problemática hay para el divisor antes comentado (fig. 4), que parece situarse en el periodo de Boco I (110-80 a.C.) y sus sucesores (ca. 80-33 a.C.), por lo que sería una metrología distinta.

Este problema no existe para las emisiones broncíneas de Sifax (213-202 a.C.), cuyo estudio, realizado por Mazard (1955: 18-21), ha posibilitado sistematizar las monedas en sendas series. En la primera de ellas encontramos un cuarto de unidad (Mazard 1955: 20, $\mathrm{n}^{\circ} 9$ = Alexandropoulos 2007: 393, no 3), de metrología e 
iconografía similares $(3,0 \mathrm{~g}, 16 \mathrm{~mm}$ ) (jinete portando bastón), pero con un glóbulo bajo el caballo. Partiendo de esto, nuestra nueva emisión podría ubicarse aquí, pero la ausencia del glóbulo imposibilita hacerlo. No sólo eso, sino la leyenda curvada del reverso, como aparece en nuestra emisión, es atípica de las primeras series, cuyas leyendas siempre están rectas y en cartelas cuadrangulares. El estilo es otro factor que lo aleja radicalmente: mientras que los caballos de los bronces númidas de Sifax tienen buenas hechuras, las que poseen los caballos de nuestras dos monedas son significativamente menores y con cierta tendencia al esquematismo.

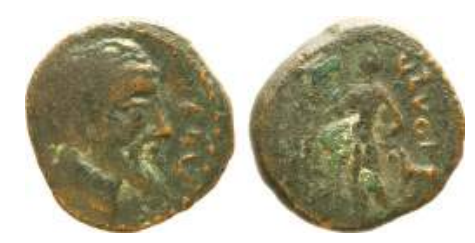

Fig. 5: Bronce de Boco I con leyenda ȘYG`N. Bibliothèque Nationale de France, inv. 739 (Foto: L. Callegarin). Medidas: 7,21 g/ 22 mm / 6h.

Al no presentar en el reverso glóbulo como indicación de su valor (propio de las primeras acuñaciones reales de Sifax y por influencia púnica), no creemos que esta nueva emisión deba enmarcarse en las emitidas por Sifax y Verminad (213-200 a.C.), este último con moneda argéntea solamente y titulatura clara, sino más bien entre las de Boco I (110-80 a.C.) y sus sucesores (ca. 80-33 a.C.).

Amela Valverde (2017: 194), tras publicar la subastada en Classical Numismatic Group (fig. 3), concluye también que la moneda debió ser emitida por Boco I o Boco II, con su consiguiente efigie. El nombre del monarca en el anverso no se menciona, aunque sí el del taller en el reverso, es decir, lo mismo que ocurre en la moneda de la fig. 4, adscrita a otra emisión, pero caracterizada con toro. Incluso observamos una misma ejecución de reversos.

De nuevo el estilo nos sirve para deducir ciertas proximidades cronológicas: el retrato de nuestra serie es muy similar al de Sifax (primeras emisiones), pero sobre todo al de Boco I (fig. 5; tipo en Mazard 1955: $\mathrm{n}^{\mathrm{o}} 107 \mathrm{y}$ Alexandropoulos 2007: 405, no 42a y lám. 7), a quien Alexandropoulos atribuye todas las series de bronce de la ceca de Siga (Alexandropoulos 2007: 194-196). Pero hay una diferencia, la posición de la cabeza es siempre a la izquierda por Sifax, y en la gran mayoría de las monedas a la derecha por Boco I (como en nuestros dos ejemplares, figs. 1 y 3). Otro elemento esencial es la epigrafía. En las leyendas de Sifax, las letras son púnicas, y en las leyendas de Boco I y de la ceca de Siga son neopúnicas. Dentro de los nombres de Sifax (SPQ), de Boco I (BQS) y de Siga $\left(\mathrm{SYG}^{\star} \mathrm{N}\right)^{5}$, hay solamente una letra en común: la samek.

La samek empleada en la leyenda de Siga es muy similar a la que encontramos en el nombre de Boco I (fig. 6). No hay duda que la leyenda de nuestro ejemplar monetario pertenece más al ámbito de la época de Boco I que a la de Sifax.

Los nuevos datos sobre la emisión númida de Siga y con jinete lanceando permiten una mejor definición tras dos ejemplares conocidos (figs. 1 y 3 ). Nos encontraríamos pues ante una emisión de mitades mauritanas devaluadas, acuñadas entre finales del s. II y mediados del I a.C. en la ciudad de Siga. Según Estrabón (XVII, 3, 9), Siga en estos momentos se encontraba en ruinas (Posidonio, ca. 100 a.C.), pero, gracias a la anexión del territorio de Jugurta en el 105 a.C., bajo Boco I la ciudad debió experimentar una recuperación, desempeñando un destacado papel como nueva capital real de Mauritania. Ya en el 104 a.C., Boco I, ahora cliente de la República romana, apoyaría a los romanos poniendo a su disposición tropas auxiliares para rescatar Lilibea, en Sicilia, asediada por esclavos rebeldes (Diodoro, XXXVI, 5, 4). Podemos suponer que la imagen del reverso de nuestra serie rinde homenaje a estas famosas tropas de jinetes, en el transcurso de la Segunda Guerra Servil.

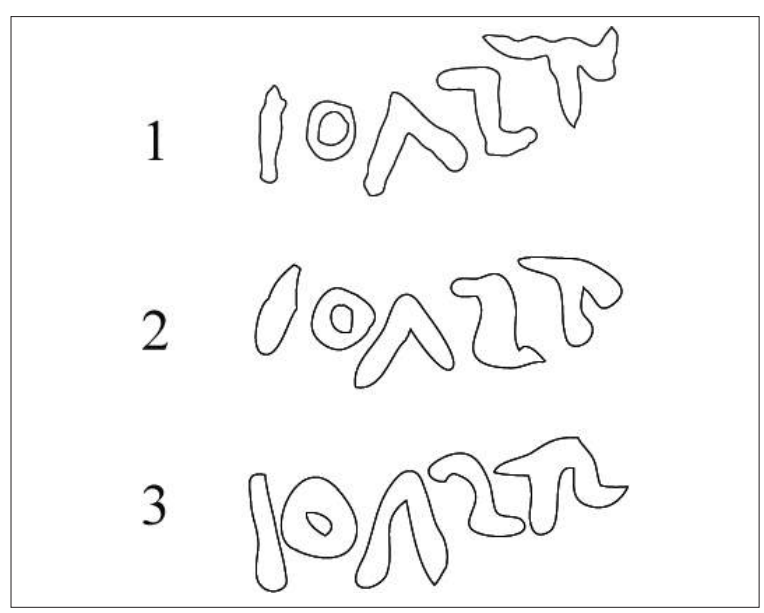

Fig. 6: Diferentes leyendas de la ceca de Siga (1. CNG 100, lote 1615, 2015; 2. Col. privada, ex Lucernae; 3 . A nombre de Boco I: BnF inv. 738, Mazard 1955: n 111). 
Las piezas de esta nueva emisión tienen un peso medio de 3,52 g (2), cuya metrología es similar a la propia de las emisiones de Siga (Mazard 1955: $n^{\circ} 578$ ) y de Shemesh a nombre de Boco I (Mazard 1955: $\mathrm{n}^{\circ} 113$, con peso de $3,8 \mathrm{~g}$ ), ajustándose también a las tardías procedentes de las cecas de Camarata, Timici, Tamuda y Sala. En cuanto a los cuños hasta ahora documentados en la emisión de Siga con jinete lanceando, existen únicamente cuatro, tanto de anverso como de reverso, todos ellos diferentes (figs. 1 y 3), siendo, por tanto, una emisión relativamente reducida.

\section{NOTAS}

1. No estamos totalmente convencidos de la lectura de la primera letra, podría ser también "S" (una samek).

2. En otras fuentes iconográficas, como en la conocida estela de Abizar (Cabilia, Argelia), el soldado númida también es representado con jabalinas.

3. Un jinete similar también se halla representado en un raro denario de Juba II (Alexandropoulos 2007: 419, n 154U y lám. 8), pero es el rey lanceando a un pequeño jabalí.

4. Esta pieza fue incluso compilada como unicum por Amela Valverde (2017).

5. En la leyendas de Boco I y de la ceca de Siga, la letra S tiene a veces una grafía poco convencional que la acerca a las $\breve{S}$ (shin) o Ș (sadé).

\section{BIBLIOGRAFÍA}

ALEXANDROPOULOS, J. (2007): Les monnaies de l'Afrique antique. 400 av. J.-C. - 40 ap. J.-C., Toulouse.

ALEXANDROPOULOS, J. (2013): L'atelier monétaire de Siga: esquisse d'une histoire, L'homme et la Société 6, 19-28.

AMELA VALVERDE, L. (2017): Moneda inédita de Siga (Numidia occidental), Varia Nummorum 7, 189-196.

JENKINS, G. K. (1969): Sylloge Nummorum Graecorum. The Royal Collection of Coins and Medals, Danish National Museum. North Africa, Syrtica-Mauretania, Copenhague.

MAZARD, J. (1955): Corpus Nummorum Numidiae Mauretaniaeque, París.

MÜLLER, L. (1860): Numismatique de l'ancienne Afrique, Copenhague. 